\title{
LA TRASLACIÓN AÉREA DE SANTIAGO APÓSTOL
}

\author{
Por \\ «BOROBÓ»
}

A la memoria de Celestino Luis Crespo, creador de la Teoría del empalme

\begin{abstract}
$\mathrm{Al}$ abordar este mágico asunto de «La traslación aérea de Santiago Apóstol» confieso que me he dejado guiar por un párrafo leído en una voluminosa Historia General de España y de sus posesiones de Ultramar, editada en 1874 y de la que nadie se acuerda, pues evidentemente su ingenuo y piadoso autor, D. Eduardo Zamora y Caballero, supongo que nada interesante aportó a la investigación de nuestro pasado. Pero suyas son las líneas tan candorosas, que si no fueran demasiado largas, podrían servir de lema a este ensayo histórico; pues, aunque parezca mentira, expresan con toda su anacrónica credulidad decimonona, el trasfondo del pensamiento impío de quien hasta ahora tenía por lema aquel, mucho más escueto, de su antiguo maestro y mentor Ánxelo Novo: «Como liberal, mendaz y volteriano, amén de masón».

Mas, oigamos lo que escribía el bueno de D. Eduardo Zamora y Caballero:
\end{abstract}

"CUADERNOS DE ESTUdIOS GALLEGOS", Tomo XLVII, Fascículo 112, Santiago 2000. 
"Acaso en los tiempos que alcanzamos, en que el racionalismo hace tantos esfuerzos por destronar a Dios, para sustituirlo con cualquiera aberración de una inteligencia calenturienta; en que no se quiere creer en los milagros, pero se cree en las mesas giratorias; que se proclama la soberanía absoluta de la ciencia, para caer en la ridiculez del espiritismo, este relato (el de la traslación y la invención del Cuerpo de Santiago el Mayor) arrancará una sonrisa de desdén a los labios de ciertos hombres superiores, o que imaginan serlo. Nosotros somos pequeños, y escribimos para los pequeños. Tenemos fe, creemos en Dios, creemos en los milagros, y no rechazamos lo sobrenatural, sin más razón que la de que no podemos explicárnoslo. Aún dentro de los límites de lo natural, hay muchas cosas inexplicables, y sin embargo existen. La electricidad ha existido desde el principio del mundo, y pasaron muchos siglos antes de que la ciencia la encontrara y pudiera explicarla. Ningún sabio ha podido explicar aún el misterio de la generación de la especie humana, y todos los días nacen centenares de hombres. Los que niegan los milagros porque no los comprenden, debian negar su propia existencia, que es una cosa también incomprensible» ${ }^{1}$.

Esto se escribiría seguramente en el año de la I República española, que fue el 1873, anterior al de su publicación. Desde entonces sabido es que las ciencias adelantaron una barbaridad, pero muchísimos fenómenos continúan siendo incomprensibles. Y quizá haya tenido razón también el fabuloso profesor Pedro Martul, no obstante sus antecedentes rojos y agnósticos como los míos, al escribir un día en El Eco Franciscano que «creer en los milagros es tan legítimo como tener fe en la penicilina».

Por ello, al iniciar nuestro tema, podríamos parodiar la célebre frase de Leiras Pulpeiro, atribuida luego a D. Vicente Risco, e incluso a Álvaro Cunquero; quien ya en una anécdota de la revista Finisterre había dejado constancia de que pertenecía a su ilustre vecino, el incrédulo poeta y médico mindoniense ${ }^{2}$. De ahí que en vez de decir aquello de «eu non creo nas meigas, mais habelas hainas», diré «eu non creo na traslación doApóstol, máis habela a houbo» y añadiría «polo aire, dende Bisria a Compostela». E non naquel carro de bois da Reina Lupa, o de toros milagrosamente amansados, o quizá castrados, pero sin duda castreños, que subían al Pico Sacro, el pagano Monte Ilicino. 
Pues en esta cuestión de los milagros opino que se debe dar preferencia en cada caso a la versión más antigua, históricamente contrastada, que existía de cada uno. Y dada la esencia maravillosa de ellos, lo lógico, y lo mágico, es que escojan los hagiógrafos, entre las variantes del milagro que exalten, al más inverosímil e inexplicable de que dispongan.

Por tanto, es mejor que el origen del milagro se pierda en la noche de los tiempos y de que su concepción responda al vuelo de la más anónima y genial fantasía. Sin que nunca pudiese ser explicado científicamente, porque entonces dejaría de ser milagro y se trocaría en una lección de física o de bioquímica.

Pero los milagros han de tener una base real, conjugada con su prodigiosa naturaleza. De ese modo, deben de pertenecer, más bien al mundo literario del realismo mágico, que al religioso de la teología escolástica. Corresponden a la esfera de la creación humana, más que a la realidad existencial de los hombres. Mucho más que lo verdaderamente vivido, persiste en el acervo de la humanidad lo que los hombres, y las mujeres, han creado, han inventado, han imaginado a lo largo de los tiempos: los mitos, las religiones, las supersticiones, la filosofía, la literatura, el derecho, con los billones de folios de sus inacabables pleitos, y el producto de la infinita serie de ciencias y saberes, cuyo único origen reside en las elucubraciones, más o menos calenturientas, de la mente humana. Y con mayor o menor valor estético.

Por ello, ante cada mito, cada novela o cada milagro, inventado por quienesquiera de nuestros antepasados, y desde mi postura de considerar la historia como una hermosa y entretenida diversión -tal como confesé en el proemio de mi libro La raiz mágica del Primero de Mayo- lo que me importa es que el lector decida, al modo del lírico marinero de Gil Vicente $^{3}$,

$$
\begin{aligned}
& \text { Si la nave o la vela } \\
& \text { o la estrella (del milagro) } \\
& \text { es tan bella } \\
& \text {... como yo imagino esta historia... }
\end{aligned}
$$

Tal era mi posición histórica en el momento en que escribí, durante el invierno (1992-93) un insólito anaco para el Correo do 93, que publicaba semanalmente el Consorcio de Santiago ${ }^{4}$. 
Pertenece a una serie de artículos, escritos en mí gallego, escasamente normativizado, en la cual venía divagando sobre cuestiones jacobeas, con motivo de la Gran Perdonanza de 1993. Que se me perdone por ello, si incurro tanto en faltas gramaticales como en errores históricos o teológicos, pues no dejo de ser un viejo periodista habituado a escribir en español, sobre lo humano, pero nunca acerca de lo divino. Y al emplear este gallego en los anacos de esa serie que traigo aquí a colación, me parece lícito que en los Cuadernos de Estudios Gallegos, se use, aunque parvamente empobrecida, la lengua inmarcesible de Rosalía, alternando con la de Valle-Inclán, no menos lesionada por mi y entreveradas con algunos latines macarrónicos. Dicho esto entro en el asunto:

\section{LA PREHISTORIA DE COMPOSTELA}

\section{Veu polos aires o corpo do Apóstol}

conforme di a Epístola do Papa León

Nas súas Notas críticas sobre el origen del culto sepulcral a Santiago de Compostela, monseñor Guerra Campos, interroga: «¿Qué se esconde bajo la extrañísima intervención del Sol en el traslado del Cuerpo desde Iría a Compostela? $\rangle^{5}$.

Este misterio encérrase dentro dun párrafo da arcana Epístola chamada do Papa León. Foi transcrita así en Latín, por López Alsina: Septima namque die requievit ratis inter dous rivos Ulia et Sare in locum dicitur Bisria, et sic inde levatum est corpus eius centro solis in area ${ }^{6}$.

Ou sexa, en galego, que despois de navegar sete días a barca -ratisdo Apóstol, recala nun lugar chamado Bisria, situado na confluencia dos ríos Ulla e Sar. E unha vez chegado alí, o Corpo de Santiago e levantado polos aires cara o sol.

Logo di o suposto Papa León que os discípulos do Apóstol desconsolados ante a prodixiosa desaparición, anduveron unha distancia de doce miliarios, ata topar o Corpo xa sepultado sub arcis marmoricis.

Pois ben, este feito milagroso de que o Corpo de Santiago Boanerges chegase por vía aérea á futura Compostela, moitos séculos antes de que estuvera en funcionamento oAeroporto da Labacolla, pasóu absolutamente desapercibido ao cronista, inda que ó foi da cidade xacobea durante varios anos.

"CUADERNOS DE ESTUdIOS GALLEGOS", Tomo XLVII, Fascículo 112, Santiago 2000. 
De tal despiste, asimesmo, participou a inmensa maioría dos escritores que ao tratar da traslación do Fillo do Trono, sempre insistiron na lenda dos touros bravos da Raiña Lupa transportando no carro dende Padrón deica ladeira occidental do Castro de Lovio, o santo cadáver de Jacob, o de Zebedeo, sin que fixesen ningún caso do que revelaba a chamada Epístola do Papa León.

Iste documento fundamental da Historia xacobea foi considerado por destacados investigadores como de «una barbarie espantosa», ata que o estudióu científicamente Fernando LópezAlsina, no seu libro tan esclarecedor: La ciudad de Santiago de Compostela en la Alta Edad Media.

Tal epístola atribuida por D. Antonio López Ferreiro ao Papa León III -sumo pontífice no tempo da Invención da Tumba- foi publicada na sua magna Historia de la Iglesia de Santiago ${ }^{7}$, cotexando os que para él eran os tres textos que se conservaban dela: o do Códice Calixtino, o do Códice Escurialense e o de Breviario de Évora. En ningún deles consta que o Corpo do Apóstol fose levantado polos aires cara o sol. E solamente o Escurialense fala de Bisria.

Mais López Alsina estudiou os tres textos máis antigos da misteriosa Epístola, dos cales soamente tamén o Escurialense, fora reproducido por López Ferreiro. Os outros dous, que cotexóu López Alsina foron un relacionado con Limoges, e a versión de San Martín Pinario, chamado do Monte Sacro, polo o seu editor Rubén García Álvarez

Do cotexo e análisis comparativo de istos tres textos máis vellos da Epístola deduxo o concienzudo investigador que debéu existir un arquetipo perdido dela na primeira mitade do século IX; polo tanto no tempo da Invención, o descubrimento, do sepúlcro do Apóstol, polo anacoreta Pelayo e o bispo Teodomiro; que LópezAlsina sitúa-coma veréi logo-despóis do 818. E nese arquetipo, sen dúbida, afirmábase que sic inde levatum est corpus eius centro solis in area ${ }^{6}$.

\section{EL VUELO EN EL CODEX CALIXTINUS}

Entre «a inmensa maioría dos escritores que ao tratar da traslación do Fillo do Trono» ignoraron el hecho milagroso de que el Cuerpo del Apóstol llegase por vía aérea a la futura Compostela, no cabría incluir a Filgueira Valverde. Pues en su precioso Libro de Santiago -publicado ya en

"CUADERNOS DE ESTUDIOS GALLEGOS", Tomo XLVII, Fascículo 112, Santiago 2000. 
1948, y reeditado pulcramente, sin ninguna alteración, en 1991, con las bellísimas ilustraciones de José Sesto9-al discurrir Filgueira acerca $D e$ los signos jacobeos, dice refiriéndose a La estrella:

"En la versión de Limoges de la carta atribuida al Papa León III se incluye una extraña leyenda de Santiago: Cuando los varones apostólicos desembarcaron en Iria el cuerpo del Evangelizador, los sagrados despojos se elevan, por los aires, hasta llegar al mismo centro del Sol».

Este motivo no vuelve a aparecer, según escribía Filgueira en 1948, y repite en 1991, «ni en las versiones de la traslación, ni siquiera en las de tan discutida Epístola». Sin embargo ya veremos como este mágico motivo se halla también en otros trasuntos de la Epístola leonis que han ido apareciendo en estos años, aparte de la lemosina; la cual se conocía desde el último año del siglo pasado, o sea el 1900; cuando la dio a conocer el P. Duchesne en Annales de Midi, en su célebre y polémico estudio acerca de los Milagros de Santiago ${ }^{10}$.

Por ello, no fue leída a tiempo esa versión lemosina por D. Antonio López Ferreiro, para poderla mencionar en el tomo I de su Historia de la Iglesia de Santiago, impreso en el año 1898, donde estudia ampliamente, en su capítulo IV ${ }^{7}$, los documentos referentes a la Traslación de Santiago Apóstol. Ya queda dicho que únicamente investigó los trasuntos del Codex Calixtino, del Escurialense (descubierto por el P. Fita en 1880) y del Breviario de Évora, en los que no figura la ascensión astral del Apóstol. Pero sí transcribe el texto de la gran leyenda floriaciense (estudiada por el aludido P. Fita), escrita según él por un monje anónimo del monasterio de Fleury, en Francia, en el siglo X, y donde todavía se dice Atque usque ad poli centrum splendore igneo rutilatis est elevatus, et ad locum suae tumulationi proximum ${ }^{11}$.

Y por si fuese poco, López Ferreiro también reproduce en su documentadísima Historia el himno del Codex Calixtino sobre «la traslación del beato Jacobo según el Papa León y el maestro Parucha», que da en verso la variante más antigua, semejante a la lemosina, y distinta, por tanto a la dada en prosa, más moderna y menos maravillosa, por el mismo Calixtino ${ }^{12}$.

Pero el insigne canónigo se limita a transcribir la leyenda floriaciense y el himno del maestro Parucha, sin prestar atención positiva o negativa al

"CUADERNOS DE ESTUDIOS GALLEGOS", Tomo XLVII, Fascículo 112, Santiago 2000. 
prodigioso vuelo de Santiago, que en cuanto al texto del himno, ha sido traducido así por D. Abelardo Moralejo:

Por tanta gloria, ;oh milagroso encanto!, El propio Sol con sus rayos el santo Cuerpo por el celeste espacio lleva Desde Iria a donde su iglesia hoy se eleva.

\section{EL CÓDICE LEMOSINO}

Así que dos siglos y pico después de haberse escrito «en letra visigoda de finales del siglo IX, o ya del X, añadida en una página en blanco de un manuscrito de lengua franca procedente de Saint-Martial de Limoges $\rangle^{13}$ todavía se canta en la catedral de Santiago el maravilloso suceso que se refleja en ese primitivo trasunto de la Pseudoepístola del Papa León. Pues el maestro Parucha, que compuso tal poética lección, aunque su nombre suena a italiano, según el mismo P. Fita, pudo ser «alguno de los muchos maestros (cantores) que florecieron en el claustro de la Catedral compostelana durante el siglo XII o a fines del anterior ${ }^{11}$.

Ese manuscrito lemosino, «una de las más ricas joyas paleográficas del siglo IX» ${ }^{14}$, se conserva actualmente en la Biblioteca Nacional de París. Supo de él, posteriormente, López Ferreiro, que ya lo menciona en el primer volumen de Galicia histórica. Luego el P. García Villada se ocupa de esta antigua versión de la Pseudoepístola en su Historia eclesiástica de España ${ }^{15}$ y la pone al alcance por ello, de cuantos, ignorándola, discurren desahogadamente sobre la leyenda jacobea. De ese texto ha hecho su edición crítica paleográfica A. Mundo, en Hispania Sacra, ya en 1952, en la monografía titulada El Cod. Parisinus Lat. $2036^{6}$.

Otra versión parecida a la del Códice lemosino, es la ya mencionada antes, que halló el médico y abnegado investigador de la Alta Edad Media gallega, Rubén García Álvarez, en el Archivo Histórico Nacional de Madrid, al examinar los documentos procedentes del monasterio de San Sebastián de Pico Sacro, y cuyo contenido publicó en la revista Compostellanum. Allí también consta aquel hecho maravilloso: Corpus eius centro solis aerea $^{8}$.

Forma parte del primer ensayo historiográfico jacobeo, que según Rubén Álvarez, ha sido la Historia del Monasterio de Montesacro, asen- 
tada en un códice vetusto. Fue compuesto por el diácono Gonzalo Rodríguez, entre 1029 y 1090. Y contiene además, entre otros documentos, el acta de la consagración de la Iglesia de Santiago, en el año 899. Del Códice vetusto se trasladó el opúsculo a un pergamino suelto. Este pasó luego desde el tesoro de la catedral de Santiago al cenobio del Montesacro y de aquí al monasterio de San Martín Pinario.

Aparte de las recensiones ya mencionadas de la Pseudoepístola, el gran investigador Balduino Gaiffier, en sus «Notas sobre algunos documentos relativos a la Traslación de Santiago en España», publicados en Analecta Bollandina, da noticia de otra hallada también en la Biblioteca Nacional de París en 1971, por los bolandistas, que constituyen un ilustre grupo de jesuitas consagrados a la investigación histórica. Gaiffier informaba también acerca de otro texto encontrado en la Biblioteca Casanetense, o sea la del martirizado Monasterio de Monte Casino, en la Guerra Mundial, y que Guerra Campos publicaría en el $\mathrm{n}^{\circ} \mathrm{I}$ de Compostellanum.

Y aún han ido hallándose otros textos medievales de la polémica Epistola en las bibliotecas de Bruselas, Copenhague, etc. ${ }^{6}$.

\section{EL SERMÓN DEL PAPA CALIXTO}

Podría ser considerado este maravilloso viaje aéreo de Santiago Apóstol como una de «las invenciones apócrifas que muchos insensatos y otros que torpemente cayeron en la herejía, que de nuestro Santiago y de su traslación se han atrevido a inventar $\mathrm{y}$, aún lo peor, que han consignado por escrito». Tal como se condenaba, en el sermón Veneranda dies del Santo Papa Calixto que forma parte del Liber Sancti Jacobi ${ }^{12}$.

Así el virtual Papa rechazaba de plano lo que tales insensatos decían acerca de que el Apóstol, «sentado sobre un pedrusco, vino desde Jerusalén a Galicia por en medio de las olas del mar, cumpliendo el mandato del Señor, sin barca alguna», y otras fabulaciones sobre el mismo pedrusco, o a propósito del medio en que se hizo el viaje apostólico. «Otros igualmente -señalaba el papa predicador-, charlan que el mismo cuerpo fue traído en una nave de cristal de Jerusalén a Galicia, navegando los tripulantes sobre las olas del mar». Lo cual sería, sin duda, un viaje más transparente y que ahora podría hacerse con la mayor facilidad, en una nave hecha de ese vidrioso material.

"CUADERNOS DE ESTUDIOS GALLEGOS", Tomo XLVII, Fascículo 112, Santiago 2000. 
Sin embargo, el anatema que atañe particularmente al sistema descrito en las más antiguas variantes de la Epístola Leonis, aunque iniciando ya el mágico vuelo en Tierra Santa, es el destinado a los otros que «sueñan que los ángeles por los aires trajeron su cuerpo de Jerusalén a Galicia sin aportación humana». El anatemizado vuelo, sin ninguna escala, ni siquiera en Bisria, era desde luego de muchísima mayor longitud que el que partía tan sólo de este puerto fluvial, sito en la confluencia del Sar con el Ulla. Si descontamos, claro, la ascensión al sol; apenas doce miliarios, o ahora unos veinte kilómetros, si se va por la antigua carretera, ya que por la flamante autopista quizá sea alguno más.

Pero ¿qué autoridad tendría un pseudo Papa Calixto para condenar a un pseudo Papa León, que habría escrito su pseudo epístola, cuando menos tres siglos antes y, por ende, mucho más cerca del milagroso viaje que mencionaba? No se paraba en barras el sagrado orador, pues a todos aquellos sueños y fábulas las calificaba de apócrifos y los destruía de raíz, llegando «nuestro furor a su colmo - decía- prohibiendo bajo anatema que nadie se atreva a escribir algo acerca de él, a no ser lo auténtico, que se contiene en el códice llamado Jacobeo» ${ }^{12}$.

Acaso por esta condena papal, ha ido cubriendo un tupido velo la prodigiosa leyenda astronáutica del Apóstol pues deja casi absolutamente de ser narrada, hasta el punto de que muchos osados explotadores literarios del Camino de Santiago, y de su monumental meta, carecen de la menor idea de ella.

En compensación, hemos de agradecer al Santo Papa Calixto que condenase, en cambio, a los que sostenían que el Apóstol había echado una maldición a la tierra de Galicia para que no diera más vino en adelante. Por el peregrino motivo de que cierta matrona llamada Compostela, según contaban, embriagada con vino del país, se durmió, mientras el Señor visitaba la Basílica, y no pudo avisar de ello al Apóstol que también dormía en su regazo. En el regazo catedralicio se entiende; no en el de la matrona llamada Compostela.

Posiblemente, gracias al anatema del Pontífice cluniacense, puede Galicia producir ahora tan excelentes albariños y otros sabrosos vinos de sus diversas y cada vez más reputadas denominaciones de origen. Sólo echo en falta que alguna de sus marcas no lleve el nombre de aquella matrona Compostela, tan buena bebedora, que a pesar de haber tomado una taza de más, estoy casi seguro que despertó a tiempo al Santo Patrón cuando éste recibió en su Iglesia la divina visita del Señor.

"CUADERNOS DE ESTUDIOS GALLEGOS", Tomo XLVII, Fascículo 112, Santiago 2000. 


\section{REMINISCENCIA DEL CULTO SOLAR}

Cabe imaginar que algunos de estos sueños y fábulas se contasen ya antes de la propia Invención de la Tumba del Apóstol. Existía en el primer tercio del siglo IX en los castros de Amahía un ambiente propicio para la aceptación de lo maravilloso. Todavía las viejas creencias castreñas de un pueblo panteísta, tenido después excesivamente por celta y escasamente romanizado, prevalecían con su contenido supersticioso, que apenas había conseguido desvirtuar San Martín Dumiense, mediante sus predicaciones y su libro De correctione rusticorum ${ }^{16}$. Se impuso, al revés, la creciente tendencia del catolicismo a asimilar, a hacer suyas, las ideas y las costumbres que iban hallando en su expansión por tierras paganas. De ese modo, de la fusión de la cultura mágica castreña con el culto cristiano a los santos, pudo nacer el milagro.

El obispo Guerra Campos, máximo investigador jacobeo, indica, en sus ya citadas Notas críticas sobre el origen del culto sepulcral ${ }^{5}$, la posibilidad de que la ascensión astral del Apóstol estuviese ligada al culto solar, primitivamente practicado en Galicia, y remite al lector a la obra de D. Florentino López Cuevillas, en la cual el insigne prehistoriador orensano examina ese fenómeno religioso. Acudí a lo que tenía más a mano: el capítulo sobre A Relixión, escrito por D. Floro en colaboración con el malogrado investigador portugués Rui de Serpa Pinto, y agregado a sus Estudios sobre a Edade do Ferro no Noroeste da Península $^{17}$. Luego lo reproduce, apenas alterado, en La Civilización céltica en Galicia.

Ahí, tras mencionar «un número considerable de feitos arqueolóxicos estreitamente relazoados ca simboloxía ben conocida do lume e do sol», se preguntan los autores, ¿si «os discos, as rodas, e as esvásticas das estelas, tiñan algo que ver, coma coida Leite de Vasconcelos, ca crenza na vida astral das almas dos mortos ou relazoaba-se pol-o contrario ca forza vivificadora do sol que fai resucitar periodicamente a natureza»?.Asimismo se preguntan si con tales símbolos «entraron tamén na Galicia ritos e creenzas heliolátricas o se pol-o contrario se conxugaron e fundiron con outras existentes e da mesma natureza».

Si bien lo más interesante, desde mi actual punto de vista, es la cita que hacen de la Hispania de Schulten, a propósito de que «o costume dos celtíberos de deixar os mortos abandoados no campo para que os

"CUADERNOS DE ESTUDIOS GALLEGOS", Tomo XLVII, Fascículo 112, Santiago 2000. 
esgazaran as aves de rapiña, procede da crenza de que asín eran por elas conducidas as almas a morada astral dos deuses. I é precisamente entre os celtíberos da meseta, emparentados en moitas cousas cos galegos, onde se atopan con maior abondosidade os restos de cultos heliolátricos».

Si se me permite ahora el ejercicio de la fantasía histórica, cabría imaginar que el Cuerpo del Apóstol, depositado sobre el legendario peñasco que se ablandó con su sagrado peso, pudo estar expuesto a los tremendos picotazos de las aves de rapiña, según la típica costumbre de los nativos, mientras los varones apostólicos que le acompañaban desde Jafa, se habían ido a negociar con la reina Lupa, el enterramiento en su predio, sufriendo entonces la persecución del régulo de Dubio y los zooformes percances del monte Ilicino.

Al regresar, los discípulos del Apóstol se toparían con la triste sorpresa de que su Cuerpo había volado, devorado por los buitres y cuervos. No faltaría algún castreño de Lestrove, o de la antigua Trabanca, que les diría que de esa forma, había sido conducido su alma a la morada astral de su dios: Corpus eius centro solis aerea, como se haría constar en el Códice del Monte Sacro ${ }^{8}$.

Y fue entonces, cuando «entre llantos y oraciones los siete discípulos recorren desconsolados una distancia de doce miliarios a partir de Bisria» ${ }^{6}$. Allí se topan con el cuerpo sepultado sub arcis marmoricis, en una urbe occidental, cuyo nombre todavía no se menciona.

La dificultad de esta macabra historia estriba en rehacer un cuerpo, destrozado por los pájaros como en una película de Hitchcock.

Pero a los buenos teólogos, o a los inventores de milagros más o menos insensatos, les sobraría imaginación para reconstruir la carne del santo, acaso con «la fuerza vivificadora del sol», extrayéndola de los estómagos de las aves. Pero en cuanto a los huesos... ¿qué se hicieron de los huesos del Apóstol?, pues no habría buitre que se los tragara. Lo natural sería que quedasen mondos y lirondos sobre el legendario peñasco que, siglos después, habría de ser arrojado al Sar, para evitar su continua destrucción por los peregrinos.

Aquí me atrevo a hacer una rectificación a la Epístola Leonis: Los huesos, nada más que los huesos, sin la carne, pudo ser que fuese lo que trasladaron, en el carro de toros amansados de la reina Lupa, hasta el edículo propiedad de ella; en el cual reposaba ya la carne mortal de 
Santiago el Mayor, si aceptan los lectores este maquillaje que propongo del milagro.

\section{LA MISIÓN ASTRAL DEL HIJO DEL TRUENO}

Esta maravillosa ascensión astral del Cuerpo del Apóstol tiene su respuesta -según escribe Filgueira Valverde, en El libro de Santiagoen el tema «de que fue una estrella la que, pasado tiempo, anunció la presencia de la tumba entre los robles del 'Burje Libredon'»: Deinde sacris luminaribus quan pluribus fidelibus in ecclesia Sancti Felicis de Lobio conmoratibus ostenditur.

Tal es el tardío relato, del ya bien entrado siglo XII, que aparece en la Historia Compostelana, o de los Hechos de Gelmírez. Para Filgueira esas luminarias son «lucencias de candelas, una estrella que se posa en el roble más alto, que es el que cobija el túmulo» del Apóstol ${ }^{9}$.

Pero LópezAlsina rebaja la categoría de tales luminarias, pues «aparecen «en los textos de la época como lámparas que iluminan el interior de las iglesias y contribuyen al brillo y esplendor de las ceremonias litúrgicas $»^{6}$. Por tanto, eran lámparas aquellas «extrañas luminarias, que en medio de la noche ardían sobre el bosque en el que vivía el anacoreta» Pelayo. Así son, efectivamente, arañas de iglesia en la correspondiente miniatura del Tumbo A de la Catedral compostelana.

No obstante, el finado presidente del Consejo de Cultura de Galicia, las sigue considerando «estrellas que bajan a posarse sobre el sepulcro; almas que ascienden por el camino de las peregrinaciones». La primera de ellas sería, conforme a la mágica interpretación de la Epistola Leonis, la propia figura delApóstol Santiago ascendiendo hacia el sol. «Estrella más que rayo él mismo, hijo del Trueno»...

\section{¡O sidus refulgens Hispaniae \\ Sancte Jacobe Apostole!}

...como lembra Filgueira 9 .

Mas, ¿podría quedar pendiente el alma del Apóstol, colgada de un roble, sobre su propia tumba? Rara sería esta inmovilidad en el beato Jacobo, a quien ya hace medio siglo, denominé en un artículo de Finisterre «el 
santo dinámico por excelencia, que podría ser patrón de cuatro medios distintos de transporte $\rangle^{18}$.

El destino de Santiago sería mucho más elevado que el de servir de «lucencias de candelas» en el bosque de la Invención.

El propio Calixtino retocaría versos del gran poeta cristiano, San Venancio Fortunato, obispo de Poitiers, para exaltar la misión astral del Hijo del Trueno:

"Desde el país gallego a las estrellas sube», se lee en la loa De Virginitate, y en otro poema se señala que "por sus méritos la fe le levantó hasta las estrellas» ${ }^{12}$.

Ya es Santiago un astro que rẹfulge en el cielo de la Cristiandad, «como el lucero, atravesando las llanuras marinas del Océano, cual pregonero de la luz del día, con su salida ahuyenta las sombras de la noche» proclama el Papa Calixto en otro sermón. Y el Apóstol-estrella se multiplica prodigiosamente hasta el infinito, trocándose en la Vía Láctea, el luminoso Camino de Santiago, tal como Filgueira Valverde advierte:

"Pero no es tan sólo esta reveladora estrella que se posa sobre el roble de Libredón; es todo el camino de estrellas que cruza los cielos y que llamamos, del griego, por su palor lechoso, Galaxia, el que sirve en las leyendas para la revelación de la tumba»?.

Y a continuación D. José Fernando relata lindamente la visión de Carlomagno, que se narra en el libro del «Pseudo Turpin», cuarto del Codex Calixtinus: «Cuando el Apóstol Boenerges se le apareció envuelto en su claridad de rayo y estrella».

El Pseudo Arzobispo, más prosaico, se limita a informar de que «un caballero de apariencia espléndida y mucho más hermosa de lo que decirse puede, se le apareció en un sueño durante la noche» al Imperante. Y repitió la visita un par de veces. Carlomagno estaba intrigado por el camino de estrellas que veía por las noches, y que se extendía desde el Mar de Frisia hasta Galicia «en donde entonces se ocultaba, desconocido, el cuerpo de Santiago».

La incógnita sobre aquel camino, en el cual pensaría al quedarse dormido, se la resolvió en sueños el apuesto caballero: Conducía hasta el 
territorio de su propia tumba que se hallaba en poder de los sarracenos. Y el Emperador debía ir con un gran ejército «a liberar mi camino y mi tierra», le indicaba el hijo de Zebedeo ${ }^{12}$.

Luego el Arzobispo Turpin escribe la gran patraña, fuente de los cantares de gesta del ciclo carolingio, que tanta trascendencia tuvo en la literatura francesa, sobre la peregrinación de Carlomagno a Santiago, llegando a Padrón, donde «clavó una lanza en el mar». Aunque sería más bien en Rianxo, quizá en la playa de Tanxil... Y después conquistó toda España.

La verdad histórica y las contradicciones cronológicas no impidieron al afrancesado cabildo medieval compostelano dar como verídicas estas fantásticas hazañas del Emperador. Incluso se adelanta la fecha del descubrimiento de la Tumba, para que éste pudiese ser conocido por Carlomagno, antes de morir el 28 de enero del 814. Pero LópezAlsina puntualizó ${ }^{6}$, lo que yo luego divulgué en otro artículo del Correo do $93^{19}$ : Que Teodomiro, su descubridor, hasta después del 818 no fue obispo de Iria, pues quedan documentos firmados en ese cuatrenio por su predecesor Kindulfus.

Y la rota de Roncesvalles, el acontecimiento culminante del relato de Turpin, había ocurrido justo cuarenta años antes, en el 778.

Pero cabe que Carlomagno haya podido enterarse de la existencia de la Tumba de Santiago con mucha anterioridad a la Invención de Teodomiro. Bastaba que leyese el arquetipo perdido de la Epistola Leonis que estaba dirigida a los regibus francorum, et vandalorum, gotorum et romanorum, los cuales habían reinado ya varios siglos antes que Carlomagno.

Y como en la misteriosa Epístola se afirmaba que había ascendido el Apóstol Santiago hasta el Sol, no parece excesivamente exagerado que el Imperante de la barba florida le viese aparecer en sueños, acaso procedente de los espacios siderales.

Carlomagno reunía en su testa las coronas de casi todos aquellos reyes a los que había sido dirigida tan arcana epístola, adjudicada por López Alsina, a un patriarca León de Jerusalén, mejor que a un Papa León de Roma.

Pero el misterio se acentúa al tener en cuenta que tales monarcas representativos de la Cristiandad Occidental, reinaban en un momento histórico en el cual se denominaba romano al rey ostrogodo Teodorico. Situándose cronológicamente en un ámbito comprendido entre los años 476 y 535, cuando en Galicia dominaban los suevos ${ }^{6}$.

"CUADERNOS DE ESTUDIOS GALLEGOS", Tomo XLVII, Fascículo 112, Santiago 2000. 
Pues bien, estos años están insertos dentro del tiempo de lo que me arriesgo a titular «agujero negro de la historia de Galicia». Ya que desde el año 468, en que termina el Cronicón de Idacio, hasta el 559 en que el Biclarense empieza su historia, ni siquiera se sabe los nombres de los reyes suevos, ni cuanto sucedió además en nuestro país durante esa oscura y longuísima etapa.

Acaso en ese hondo agujero negro haya quedado oculto el misterio que encierra la Tumba compostelana y su temprano anuncio en la Epistola Leonis. Tratar de desentrañarlo, en lo posible, continuará siendo el motivo de mi diversión histórica.

MadriGalicia, 12-V-1993/12-V-1998.

\section{NOTAS}

${ }^{1}$ ZAMORA CABALLERO, Eduardo: Historia General de España y de sus posesiones de Ultramar desde los tiempos primitivos hasta el advenimiento de la República. Tomo I, capítulo XI. Madrid, 1874.

${ }^{2}$ CUNQUEIRO, Álvaro: «Correveidile», en Finisterre, Revista de Galicia, $\mathrm{n}^{\circ} 28$. Madrid, mayo, 1946.

${ }^{3}$ GIL, Vicente: Muy graciosa es la doncella. Antologías de la poesía española.

${ }^{4}$ BOROBÓ: «Véu polos aires o corpo do Apóstol conforme a epístola do Papa León», en Correo do 93, $\mathrm{n}^{\circ}$ 17. Santiago, 31-XII-1992.

${ }^{5}$ GUERRA CAMPOS, José: «Notas críticas sobre el origen del culto sepulcral a Santiago de Compostela». Separata de La Ciencia Tomista, $\mathrm{n}^{\circ \mathrm{s}} 279$ y 280.

${ }^{6}$ LÓPEZ ALSINA, Fernando: La ciudad de Santiago de Composela en la Alta Edad Media. Santiago de Compostela, 1988.

${ }^{7}$ LÓPEZ FERREIRO, Antonio: Historia de la Santa A.M. Iglesia de Santiago de Compostela. Santiago de Compostela, 1898-1909.

${ }^{8}$ GARCÍA ÁLVAREZ, Rubén: «El monasterio de San Sebastián del Picosacro», en Compostellanum, $\mathrm{n}^{\circ}$ 6, Santiago de Compostela, 1961.

${ }^{9}$ FILGUEIRA VALVERDE, J.F.: El libro de Santiago. Editora Nacional. Madrid. MCMXLVIII.

${ }^{10}$ DUCHESNE, L.: «Saint Jacques en Galicia», en Annales du Midi, $\mathrm{n}^{\circ} 12.1900$.

${ }^{11}$ P. FITA y FERNÁNDEZ GUERRA: Recuerdos de un viaje a Santiago. 1880.

${ }^{12}$ Liber Sancti Jacobi. Codex Calixtinus. Traducción por A. Moralejo, C. Torres y J. Feo. Instituto P. Sarmiento de Estudios Gallegos. Santiago de Compostela. MCMLI.

${ }^{13}$ VÁZQUEZ DE PARGA, Luis: «El 'Liber Sancti Jacobi' y sus textos referentes a la leyenda de Santiago». En Las peregrinaciones a Santiago de Compostela. Consejo Superior de Investigaciones Científicas. Madrid. 1948/49.

"CUADERNOS DE ESTUDIOS GALLEGOS", Tomo XLVII, Fascículo 112, Santiago 2000. 
${ }^{14}$ CASAS, Álvaro de las: Santiago de Compostela, corazón de Europa. Emecé editores. Buenos Aires, 1939.

${ }^{15}$ GARCÍA VILLADA, Z.: Historia Eclesiástica de España. Madrid. 1929-1936.

${ }^{16}$ PEDRET CASADO, Paulino: «Introducción á 'Traducción galega de obra de San Martiño de Braga De correctione Rusticorum'». Nos, Boletín mensual de cultura galega, ano 1932, Tomo V, nº 97. Edición facsimilar de Galaxia. Vigo. 1979.

${ }^{17}$ LÓPEZ CUEVILLAS, Florentino y SERPA PINTO, Rui de: «Estudos sobre a Edade do Ferro no noroeste da Península. A Relixión», en Arquivos do Seminario de Estudos Galegos. VI. Santiago de Compostela. MCMXXXIII-MCMXXXIV.

${ }^{18}$ DON GALLEGO: «Santiago en varia traslación», en Finisterre. Revista de Galicia. $\mathrm{n}^{\circ}$ 24. Madrid, enero, 1946.

${ }^{19}$ BOROBÓ: «O bispo Kindulfus retarda varios anos a invención de Santiago», en Correo do 93, $\mathrm{n}^{\circ}$ 10. Santiago. 12-XI-1992.

"CUADERNOS DE ESTUDIOS GALLEGOS", Tomo XLVII, Fascículo 112, Santiago 2000. 